producing electricity and distilling water. The immediate conclusion seems to be that plants of this kind may be economically competitive by the turn of the century.

\section{Another British Satellite}

The Science Research Council has now proudly packed the third British earth satellite off to Dallas, Texas, for compatibility tests in preparation for launching early in 1967. The intention is to find a circular orbit at a height of 325 miles. The Science Research Council has co-ordinated the construction of the satellite, which has been designed by the Ministry of Aviation. The British Aircraft Corporation has been responsible for the construction of the satellite, which weighs $198 \mathrm{lb}$.

The satellite carries five experiments designed by various groups at British universities and laboratories. The Radio and Space Research Station of the Science Research Council, with laboratories at Slough, seeks to measure radio-frequency radiation from terrestrial sources such as thunderstorms. The Meteorological Office has an experiment to measure the vertical distribution of molecular oxygen in the atmosphere of the Earth. The University of Birmingham has contributed an experiment intended to make direct measurements of the electron density and temperature at various points along the path of the satellite, while the University of Sheffield will record the characteristics of VLF radiation above the ionosphere. Finally, a group of radio-astronomers at Jodrell Bank has designed an experiment to measure the emission of radio-noise from galactic sources at frequencies too low to be detected on the ground.

\section{Biophysics at King's}

The Department of Biophysics at King's College, London, and the Biophysics Research Unit of the Medical Research Council live together in the same building in Drury Lane. The building, once a warehouse, was converted with great skill to a research laboratory, thanks to a grant from the Wellcome Trust and assistance from King's College and the Medical Research Council. The two groups of research workers are so closely integrated that it is often impossible to tell which is which.

Resting muscle has been studied by X-ray diffraction, and the method has now been applied to the contracted muscle of vertebrates. The muscle contracts momentarily and raises a lead screen, allowing the $\mathrm{X}$-ray beam to pass through the muscle for a short period of time during the contraction. Since vertebrate muscle can only contract for about one second in ten, the method needs very long exposure times unless the intensity of the X-ray beam can be increased. It has proved possible to increase the intensity by a factor of ten by passing the beam through a barrel shaped tube coated on the inside with gold. This technique, which can well be applied to other types of X-ray cameras, has shown that the sliding filament model of muscle action may well be a realistic one.

\section{Slow Machine Translation}

THFre is no immediate justification for the use of computers as automatic translation machines according to a committee of the National Research Council in
Washington. The committec, whose chairman was Dr. John R. Pierce of the Bell Telephone Laboratories, considers that machines are at present slower, less accurate and more expensive than human translators. The committee does, however, consider that computers have a valuable part to play in the development of linguistics and has therefore recommended that the United States Government should spend more money both on theoretical research and in a search for improvements in machine translation. Its report, Language and Machines, is to be had from the National Academy of Sciences-National Research Council at $\$ 4$.

The committee is almost lyrical in its assessment of how computers have helped linguistics, especially in the drudgery of preparing concordances. Tasks which used to take human beings years are now being carried out in a few weeks. The coming of the machines will transform linguistics as the development of the large particle accelerators has transformed high-energy physics, and for this reason Dr. Pierce and his colleagues would like to see an annual expenditure of between $\$ 2.5$ and $\$ 3$ million on the further development of techniques for using computers as linguistic analysts.

The committee's argument on translation by machine is based as much on an assessment of the need as on a prediction of what computers could accomplish. The committee says that the United States is already spending $\$ 22$ million a vear on translation by human beings, and that this is apparently sufficient to meet the demand for English versions of Russian and other publications. Most of the foreign language publications which scientists in the United States wish to read are published in English anyway. The committee says that it might be more expedient to persuade Americans to learn Russian than to attempt to provide a thoroughly comprehensive translation service, but if that should be insufficient, human translators-at an average salary of $\$ 6,850$ a year-are cheap at the price.

\section{Science and Putlic Affairs}

A PERMANENT institute for the study of "the role of science in human affairs" has been established at Columbia University with a grant of $\$ 1$ million from the Sloan Foundation. This, perhaps the most richly endowed so far of all the university establishments for the study of what is sometimes called the science of science, is a development of what was previously called the Council for Atomic Age Studies at Columbia University. The director of the new institute is $\mathrm{Mr}$. Christopher Wright, a physicist who worked at Los Alamos during the Second World War and who became the executive director of the Atomic Age Council. The new institute will incorporate the Advanced Science Writing Programme by means of which the university has been attempting to improve. the standard of science writing and reporting in the United States, and roughly a quarter of its funds will be spent on this work.

The academic programme of the new institute will include graduate and undergraduate teaching. The intention is that members of all the academic departments at the university will contribute to the development of the courses. Research projects already formulated include an attempt to assess the social consequences of recent developments in biology and medicine, and an attempt to define economic yardsticks 